\title{
The Impact of Cod on the Dynamics of Barents Sea Shrimp (Pandalus borealis) as Determined by Multispecies Models
}

\author{
B. I. Berenboim, A. V. Dolgov, V. A. Korzhev, and N. A. Yaragina \\ Polar Research Institute of Marine Fisheries and Oceanography (PINRO) \\ 6 Knipovich Street, Murmansk, Russia
}

\begin{abstract}
Over 50 years of research on Arcto-Norwegian cod feeding in the Barents Sea indicate that cod predation is one of the most important factors influencing northern shrimp (Pandalus borealis) population dynamics. In years when cod biomass is high the shrimp frequency of occurrence in cod stomachs declines. In addition, there is a significant inverse correlation between the abundance of cod and shrimp from 1982 to 1998. Analysis of the Russian-Norwegian cod stomach data base shows that cod at age 3-6 have the strongest impact on the Barents Sea shrimp stock and prefer to consume shrimp with a total length range of 5-10 cm. The established relationships are used in multispecies VPA and production models.
\end{abstract}

Key words: Barents Sea, cod, feeding, shrimp

\section{Introduction}

Northern shrimp (Pandalus borealis) are one of the most important commercial invertebrates in the Barents Sea with catches peaking at about 128000 tons in 198485. Investigations on the northern shrimp stock in the Barents Sea and near Spitsbergen are conducted by the principal fishing nations in the area, Russia and Norway. Biomass, catch and catch-per-unit-effort data from both countries show similar trends from 1984 to 1997. Russian and Norwegian surveys in the area show that biomass varies by a factor of 3 to 4 over time (Aschan et al., MS 1995). What are the dominant mechanisms behind these large fluctuations? The importance of cod in the interactions between commercial fish and invertebrates in the Barents Sea has been well documented (Ajiad et al., 1992; Bogstad et al., 1994; Nilssen et al., 1994). This paper examines the relationship between shrimp stock dynamics and cod predation.

\section{Materials and Methods}

Catch data for northern shrimp in ICES SA I, Div. IIa and IIb (Fig. 1) were taken from ICES Statistical Bulletins. Estimates of abundance and biomass of the commercial cod stock at age 3-15 years were obtained from the ICES Arctic Fisheries Working Group (Anon., MS 1999). Data on shrimp frequency of occurrence in cod stomachs were collected by PINRO on commercial and research vessels from 1947 to 1997 (Ponomarenko and Yaragina, MS 1984). On average, $29000 \mathrm{cod}$ from
ICES I, Div. IIa and IIb were examined for diet annually. The shrimp frequency of occurrence was calculated as the percentage of the total non-empty cod stomachs examined which contained shrimp. In addition, data from more than $86000 \mathrm{cod}$ stomachs collected during 1984 to 1996 from a joint Russian (PINRO)-Norwegian Institute of Marine Research, Bergen (IMR) database were examined. Description of methods used in the stomach sampling program are given in Mehl and Yaragina (1992). Data processing was conducted with the MAGE computer program (Mehl, 1986) developed at IMR, which groups prey species by size groups. The total length of shrimp from cod stomachs was measured from the postorbital hollow to the tip of the telson (Rasmussen, 1953). The importance of cod size on shrimp consumption was determined by calculating the cumulative percent of consumption by age group, i.e. the percent of the total shrimp biomass consumed by cod of a given age group each year, was calculated and then summed by age groups.

Biomass and abundance of shrimp in the Barents Sea and near Spitsbergen were assessed during 198498 using the standardized Russian-Norwegian methodology (Aschan et al., MS 1999). Shrimp biomass estimates are considered representative of the total population.

Single-species Virtual Population Analysis (SSVPA), and multi-species VPA (MSVPA) were used to assess the northern shrimp stock biomass in the Barents Sea. To apply these methods, the target species 


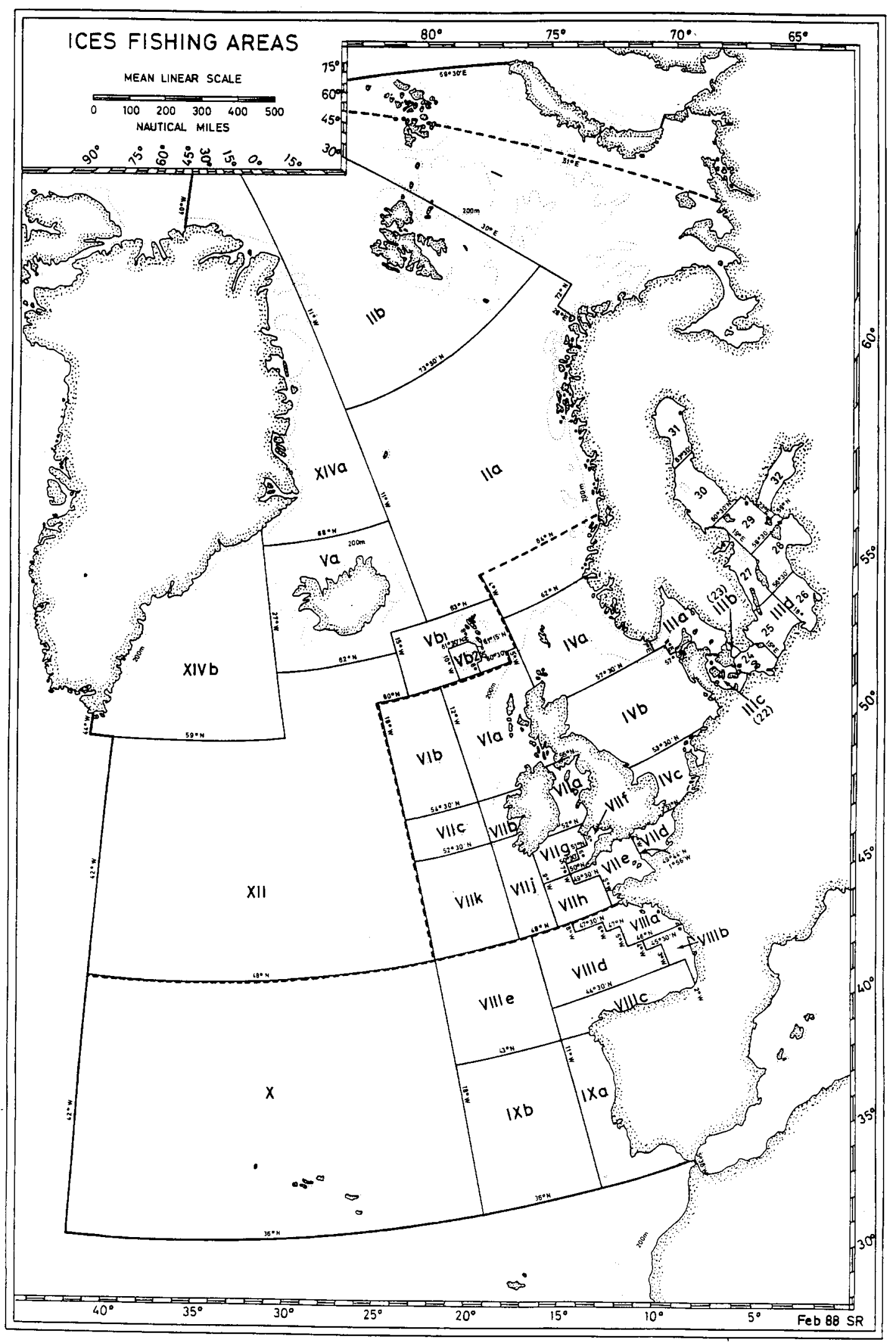

Fig. 1. ICES Fishing Areas (from ICES Fisheries Statistics, 1992). 
should be structured by age groups. However, aging of $P$. borealis from the northern Barents Sea, where most of the biomass concentrates, is problematic. Therefore, it was assumed that the age structure varies little between years, and ages were assigned as follows based on previous studies.

\begin{tabular}{lc}
\hline \hline Carapace length $(\mathrm{mm})$ & $\begin{array}{c}\text { Age } \\
\text { (years) }\end{array}$ \\
\hline$<9.8$ & 1 \\
$9.8-12.4$ & 2 \\
$12.5-16.5$ & 3 \\
$16.6-19.25$ & 4 \\
$19.26-21.5$ & 5 \\
$>21.5$ & 6 \\
\hline
\end{tabular}

Annual consumption of shrimp by cod was calculated from cod abundance, ration and the proportion of shrimp in its diet according to the commonly used Norwegian and Russian methods. Accordingly, a modified dos Santos model (Bogstad and Mehl, 1992) was used to assess food consumption by cod:

$$
R_{s}=\frac{L n 2 \times W_{s} e^{c t}}{H_{s}(2 W / W)^{b}}
$$

where $R_{s} \quad$ is the daily consumption of prey species $s$ (in $\mathrm{g}$ ),

$w_{s} \quad$ is the weight of prey species in the stomach, (in $\mathrm{g}$ ),

$T \quad$ is the water temperature $\left({ }^{\circ} \mathrm{C}\right)$,

$H_{s} \quad$ is the theoretical coefficient of digestion rate expressed as the time of $50 \%$ digestion (in hrs) of a portion of prey species $s$ by fish of the same weight at temperature ${ }^{\circ} \mathrm{C}$. Coefficient $H_{S}$ has been assumed the same for all size groups of shrimp and equal to 533 $\mathrm{g} / \mathrm{hr}$.

$w \quad$ is the total weight of stomach contents, (in $\mathrm{g}$ ),

$W \quad$ is the weight of fish (in g),

$b$ and $c$ are the coefficients.

With consumption known the shrimp stock was assessed by virtual population analysis (VPA) with a small modification to Tretyak and Korzhev (1989). Here total natural mortality is divided into two components: $M 2$ - mortality from predation by cod and $M 1$ residual natural mortality. Unlike standard VPAs a total value of catch and consumption by cod is used in the calculation instead of catch alone. If it is assumed that $M 2$ is the main component of the total natural mortality of shrimp, then $M 1$ can be assumed to be close to zero e.g. 0.01 for all size-age groups. XSA (extended survival analysis) was used to estimate start values of the coefficient $F+M$.

A fundamental difference of MSVPA from the SSVPA model described above is that MSVPA uses only catch as input information, while predation by cod is determined by the model itself, using weight proportions of prey in predator stomachs. The model estimates the size of the shrimp stock and the impact of cod on its dynamics. In the MSVPA model the total shrimp biomass is calibrated with biomass estimates from trawl surveys. An assessment of shrimp biomass dynamics using Stefánsson's model (Stefánsson et al., MS 1994) was also conducted. This is a parametric model where estimated absolute values of biomass are dependent on initial biomass $\left(B_{\mathrm{o}}\right)$ in a start year. Runs were performed for minimal, average and maximum $B_{0}$. The significance of estimates of model parameters was checked against $F$-criteria which reflects the variations of standard error (SSE) under different model parameters. Since each of the methods used in this paper has its own inherent assumptions, biases and uncertainties a comparison of results obtained with each model is essential.

\section{Results and Discussion}

The northern shrimp fishery in the Barents Sea and near the Spitsbergen archipelago is conducted by various nations, however, the bulk of the catch is taken by Norway and Russia (formerly USSR). In recent years there were two periods of high and two with low catches of shrimp (Fig. 2). These variations appear to be due to changes in stock abundance as evidenced by shrimp survey biomass estimates and synchronous changes in catch-per-unit-effort series (Fig. 2 and 3). Russian and Norwegian biomass estimates from stratified trawl

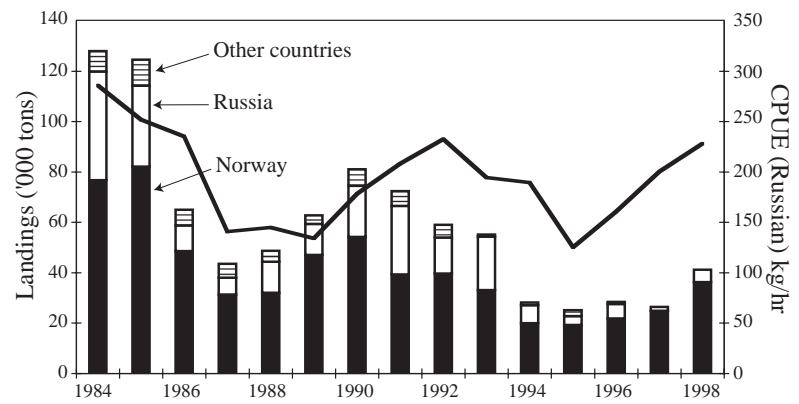

Fig. 2. Shrimp Pandalus borealis landings by country and catch-per-unit-effort $(\mathrm{kg} / \mathrm{hr})$ by the Russian vessels in the Barents Sea and Svalbard Region 1984-98. 


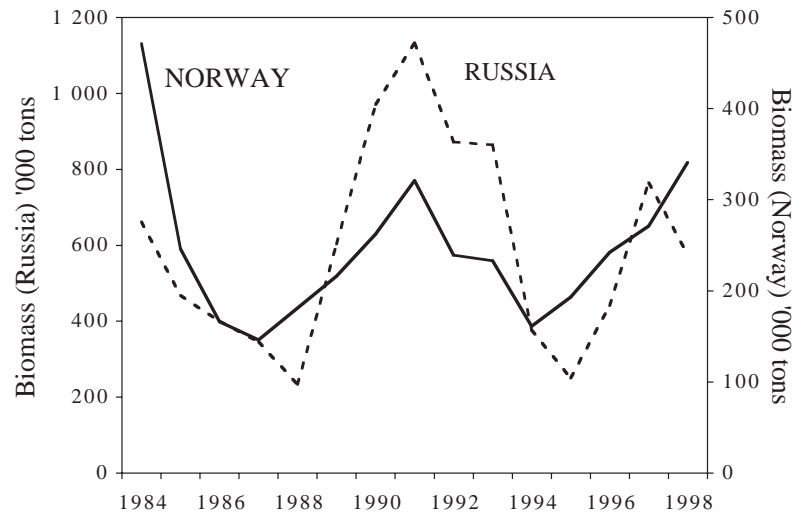

Fig. 3. Biomass estimates from Russian and Norwegian Surveys in the Barents Sea and Svalbad areas 1983 to 1998. (Norwegian data 1995-98 were kindly provided by M. Aschan, Institute Fiskeriforskning, Tromso, Norway).

surveys have generally shown similar trends (Fig. 3). Note that the difference in absolute values between Russian and Norwegian survey results is due to the use of different survey trawls.

Russian feeding studies generally show that cod stomachs predominantly contain those prey species which are most abundant in the sampling area and time (Ponomarenko and Yaragina, MS 1978). The importance of shrimp in the diet of cod appears to have changed significantly since the 1930 s when the mean annual proportion of shrimp in cod stomachs was less than $1 \%$ by frequency of occurrence and $5 \%$ by weight (Zatsepin and Petrova, 1939). Ponomarenko and Yaragina (MS 1984) observed an increasing trend in the frequency of occurrence of shrimp in cod stomachs from 1947 to 1983 and that shrimp were consumed throughout the year in a wide area. Shrimp frequency of occurrence increased to a maximum in 1981-84 (Fig. 4a), decreased thereafter, and appeared to have stabilized by the mid-1990s at about $25 \%$. Cod biomass during the same period mirrored this trend, with a significant inverse relationship between these parameters (Fig. 4b). Note also that when the cod stock was low, fluctuations of shrimp frequency of occurrence in stomachs appeared to have been larger (Fig. 4a and b).

Changes in shrimp (survey biomass) and cod abundance estimates (Anon., MS 1999) from 1982 to 1998 are compared in Fig. 5a. Note that Norwegian shrimp data were used because of the longer time series, and slightly higher correlation coefficient over Russian shrimp survey data. Also, shrimp appears to
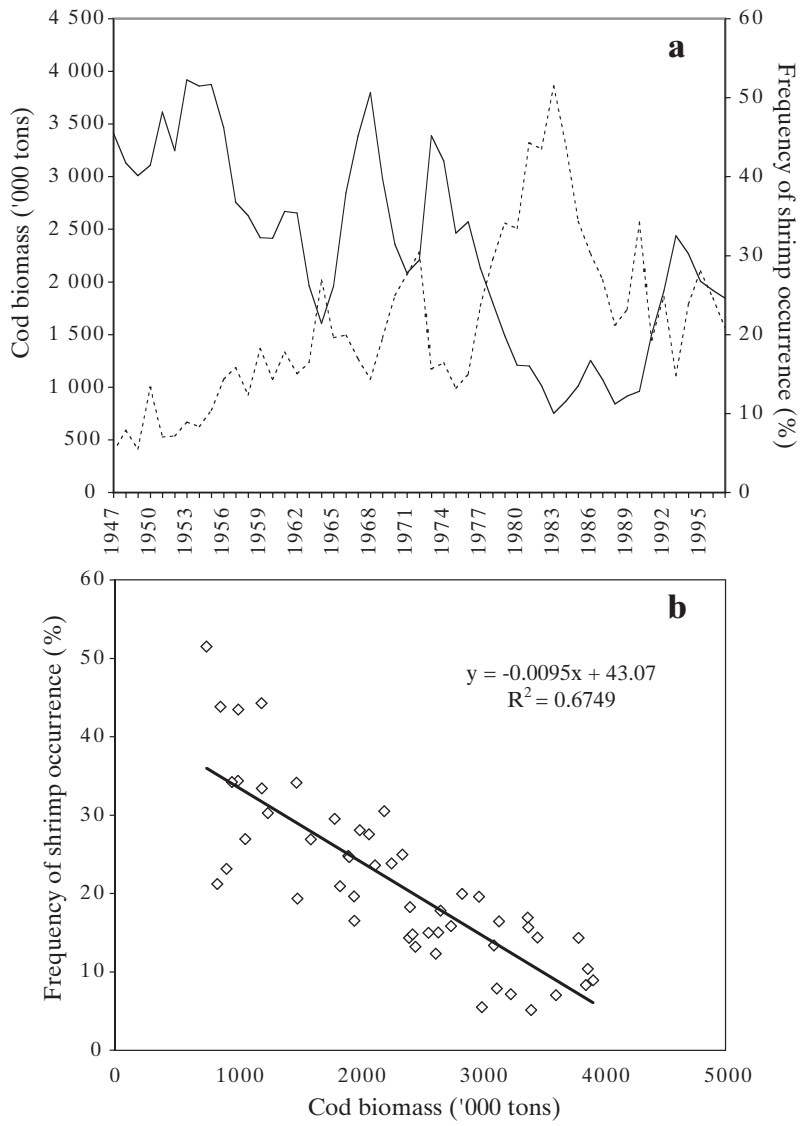

Fig.4. (a) Dynamics of Northeast Arctic cod biomass (fish at age 3-15 years, solid line) and frequency of shrimp occurrence in cod stomachs (dotted line) from 1947 to 1997), and (b) regression statistics of data in A.

lag behind cod abundance slightly, as would be expected for a causative predator-prey relationship. The appearance of several weak year-classes of cod in the early-1980s apparently decreased predation of cod on shrimp and the shrimp stock grew accordingly. Two more minima of the commercial cod stock were recorded in 1990 and 1996 corresponding to two shrimp biomass maxima (Fig. 5a). In the beginning of the 1990s several strong year-classes of cod appeared which possibly contributed to the decline of shrimp biomass.

Analysis of the joint Russian-Norwegian cod stomach database shows that the importance of shrimp in the diet of cod decreases with age. Mean annual percent by weight of shrimp in stomachs decreases from $10-12 \%$ at age $1-4$ to less $2 \%$ at age 12 years (Fig. $6 a)$. In contrast, most of the shrimp biomass is consumed by cod aged 3-6 years (Fig. 6b). Most shrimp specimens from cod stomachs had a total length of 5 to $10 \mathrm{~cm}$ (Fig. 7). The length distributions of 

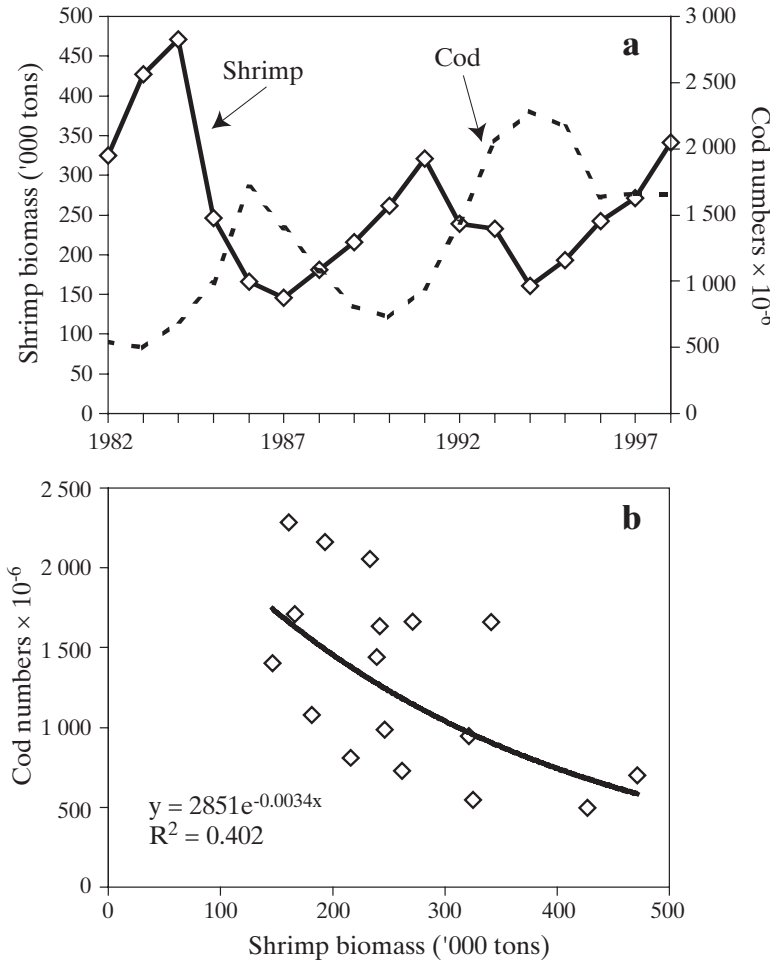

Fig. 5. (a) Dynamics of northern shrimp biomass (Norwegian survey data, solid line) and Northeast Arctic cod stock abundance (fish at age 3-15 years, dotted line) from 1982 to 1998 , and (b) regression statistics for data in A.
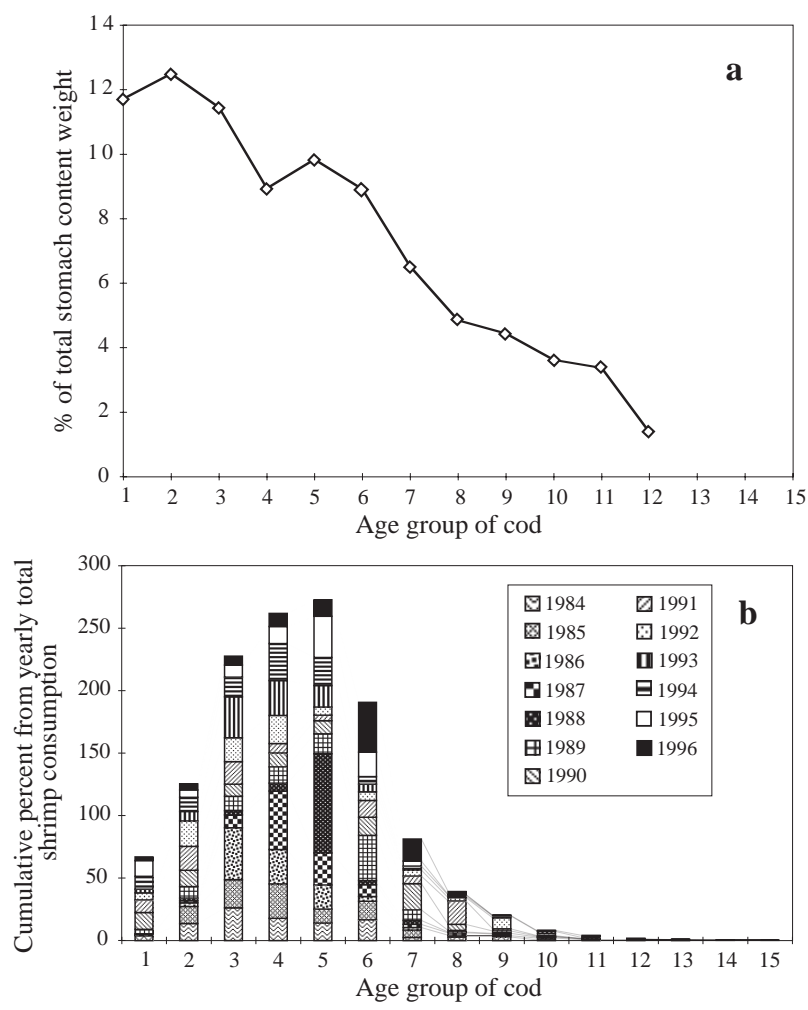

Fig. 6. (a) Shrimp importance in cod feeding, and (b) consumption by different age groups of cod during 1984-96. shrimp from all sizes of cod are very similar suggesting that, because of its small size, all length groups of shrimp are available to cod $>30 \mathrm{~cm}$. Note however that smaller shrimp are digested faster and may have been underestimated in cod stomachs.

Runs of the SSVPA model show that during 198497 the biomass of shrimp varied from $0.6 \times 10^{6}$ in 1986 and 1987 to $1.76 \times 10^{6}$ tons in 1992 (Fig. 8). SSVPA estimated shrimp biomass values were always higher than the biomass values provided by the Russian trawl surveys. Note that shrimp biomass was minimum in 1986-89 when the capelin stock, a major prey for cod in the Barents Sea, had collapsed and predation pressure on shrimp was probably higher than usual. The shrimp maximum in 1991-93 occurred when the capelin stock had recovered and predation on shrimp was probably lower.

Fishing mortality and predation mortality rates were calculated by MSVPA (Table 1). Mean natural mortality

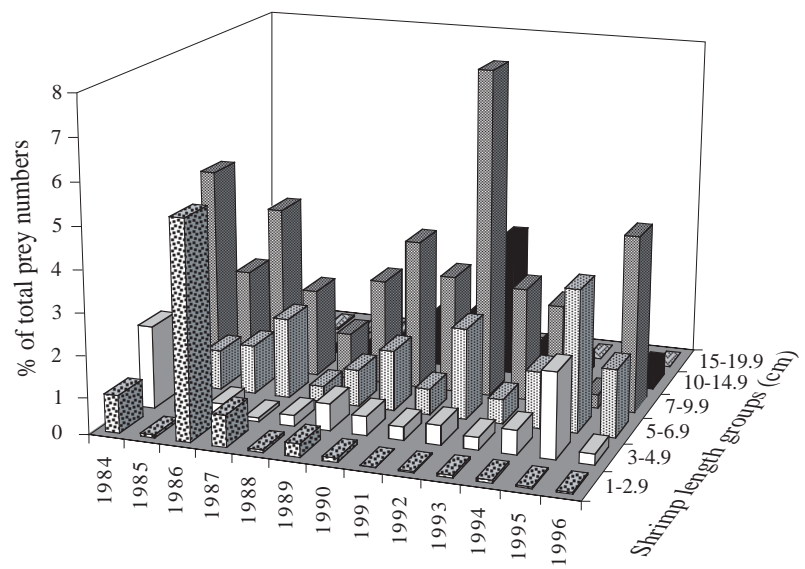

Fig. 7. Shrimp size distribution in Barents Sea cod stomachs collected during 1984-96.

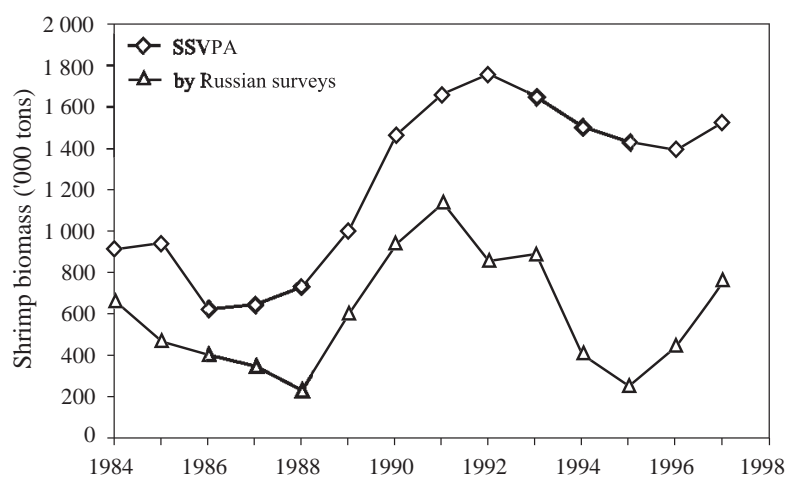

Fig. 8. Shrimp biomass in the Barents Sea from SSVPA Russian surveys. 
caused by cod predation (M2) is generally much higher than fishing mortality and appears to play a major role in shrimp population dynamics. The assessment suggests that the commercial shrimp catch is 3-4 times less than consumption of shrimp by cod. Since $F$ and $M 2$ are at times similar (Table 1), an unregulated fishery for shrimp in the Barents Sea could have an adverse impact on this stock.

The state of the shrimp stock in the Barents Sea is essentially determined by two factors: recruitment and cod predation. MSVPA calculations have shown that $15-$ $58 \%$ of the total shrimp biomass and $8-80 \%$ of individual age group biomass are consumed by cod (Table 2). Since cod prey on shrimp of all age groups, an age aggregated model could be used for comparison. A production model (Stefánsson et al., MS 1994) using shrimp catch-per-unit-effort, recruitment indices and cod predation showed fluctuations of shrimp biomass similar to Russian and Norwegian survey results.

\section{Conclusions}

Biomass, catch and catch-per-unit-effort of shrimp Pandalus borealis in the Barents Sea varied in similar ways in the period investigated.

The abundance of cod is negatively correlated with the biomass of shrimp and its frequency of occurrence in cod stomachs.

TABLE 1. Mortality from cod predation (M2) and fishing mortality $(F)$ of Pandalus borealis in the Barents Sea.

\begin{tabular}{|c|c|c|c|c|c|c|c|c|c|c|c|c|c|c|c|c|c|}
\hline $\begin{array}{l}M 2 \\
\text { AGE }\end{array}$ & 1981 & 1982 & 1983 & 1984 & 1985 & 1986 & 1987 & 1988 & 1989 & 1990 & 1991 & 1992 & 1993 & 1994 & 1995 & 1996 & 1997 \\
\hline 1 & 0.17 & 0.14 & 0.15 & 0.18 & 0.29 & 0.46 & 0.54 & 0.44 & 0.34 & 0.27 & 0.30 & 0.32 & 0.48 & 0.60 & 0.76 & 0.90 & 0.73 \\
\hline 2 & 0.08 & 0.08 & 0.09 & 0.11 & 0.17 & 0.22 & 0.25 & 0.19 & 0.17 & 0.16 & 0.16 & 0.18 & 0.23 & 0.27 & 0.35 & 0.47 & 0.40 \\
\hline 3 & 0.15 & 0.14 & 0.13 & 0.16 & 0.24 & 0.39 & 0.55 & 0.44 & 0.35 & 0.29 & 0.27 & 0.28 & 0.41 & 0.51 & 0.75 & 1.04 & 0.83 \\
\hline 4 & 0.13 & 0.12 & 0.12 & 0.14 & 0.22 & 0.36 & 0.46 & 0.37 & 0.30 & 0.25 & 0.24 & 0.26 & 0.37 & 0.45 & 0.64 & 0.90 & 0.72 \\
\hline 5 & 0.28 & 0.25 & 0.23 & 0.27 & 0.40 & 0.70 & 0.98 & 0.82 & 0.67 & 0.55 & 0.49 & 0.50 & 0.73 & 0.94 & 1.38 & 1.99 & 1.58 \\
\hline 6 & 0.24 & 0.22 & 0.22 & 0.26 & 0.38 & 0.67 & 0.76 & 0.61 & 0.51 & 0.47 & 0.48 & 0.48 & 0.68 & 0.79 & 1.06 & 1.50 & 1.28 \\
\hline Mean for age $2-5$ & 0.16 & 0.15 & 0.14 & 0.17 & 0.26 & 0.42 & 0.56 & 0.45 & 0.37 & 0.31 & 0.29 & 0.30 & 0.44 & 0.54 & 0.78 & 1.10 & 0.88 \\
\hline \\
\hline $\mathrm{AGE}$ & 1981 & 1982 & 1983 & 1984 & 1985 & 1986 & 1987 & 1988 & 1989 & 1990 & 1991 & 1992 & 1993 & 1994 & 1995 & 1996 & 1997 \\
\hline 1 & 0.00 & 0.00 & 0.00 & 0.00 & 0.00 & 0.00 & 0.00 & 0.00 & 0.00 & 0.00 & 0.00 & 0.00 & 0.00 & 0.00 & 0.00 & 0.00 & 0.00 \\
\hline 2 & 0.00 & 0.00 & 0.00 & 0.01 & 0.00 & 0.00 & 0.00 & 0.00 & 0.00 & 0.00 & 0.00 & 0.00 & 0.00 & 0.00 & 0.01 & 0.00 & 0.00 \\
\hline 3 & 0.03 & 0.05 & 0.10 & 0.13 & 0.15 & 0.04 & 0.03 & 0.04 & 0.04 & 0.07 & 0.05 & 0.06 & 0.04 & 0.02 & 0.06 & 0.03 & 0.01 \\
\hline 4 & 0.10 & 0.07 & 0.20 & 0.33 & 0.48 & 0.24 & 0.07 & 0.12 & 0.11 & 0.18 & 0.16 & 0.15 & 0.17 & 0.07 & 0.06 & 0.25 & 0.05 \\
\hline 5 & 0.09 & 0.15 & 0.17 & 0.34 & 0.85 & 0.53 & 0.36 & 0.21 & 0.23 & 0.30 & 0.24 & 0.28 & 0.26 & 0.22 & 0.10 & 0.33 & 0.08 \\
\hline 6 & 0.16 & 0.05 & 0.13 & 0.09 & 0.25 & 0.43 & 0.38 & 0.55 & 0.17 & 0.27 & 0.18 & 0.17 & 0.19 & 0.13 & 0.08 & 0.64 & 0.22 \\
\hline Mean for age $2-5$ & 0.05 & 0.07 & 0.12 & 0.20 & 0.37 & 0.20 & 0.12 & 0.09 & 0.10 & 0.14 & 0.11 & 0.12 & 0.12 & 0.08 & 0.06 & 0.15 & 0.04 \\
\hline $\mathrm{M} 2 / \mathrm{F}$ & 3.1 & 2.17 & 1.19 & 0.84 & 0.7 & 2.07 & 4.84 & 5.0 & 3.94 & 2.21 & 2.54 & 2.46 & 3.71 & 7.1 & 13.4 & 7.14 & 23.4 \\
\hline
\end{tabular}

TABLE 2. Proportion of the total Barents Sea shrimp stock consumed by cod.

\begin{tabular}{lllllllllllllllllllll}
\hline \hline AGE & 1981 & 1982 & 1983 & 1984 & 1985 & 1986 & 1987 & 1988 & 1989 & 1990 & 1991 & 1992 & 1993 & 1994 & 1995 & 1996 & 1997 \\
\hline 1 & 0.15 & 0.129 & 0.132 & 0.161 & 0.244 & 0.362 & 0.407 & 0.347 & 0.281 & 0.234 & 0.25 & 0.269 & 0.372 & 0.441 & 0.519 & 0.582 & 0.518 \\
2 & 0.076 & 0.073 & 0.08 & 0.099 & 0.148 & 0.191 & 0.215 & 0.173 & 0.154 & 0.141 & 0.147 & 0.158 & 0.203 & 0.228 & 0.289 & 0.369 & 0.332 \\
3 & 0.136 & 0.122 & 0.114 & 0.133 & 0.193 & 0.309 & 0.413 & 0.343 & 0.288 & 0.238 & 0.223 & 0.23 & 0.322 & 0.39 & 0.508 & 0.632 & 0.559 \\
4 & 0.115 & 0.105 & 0.097 & 0.108 & 0.149 & 0.252 & 0.35 & 0.29 & 0.246 & 0.195 & 0.19 & 0.203 & 0.277 & 0.343 & 0.451 & 0.54 & 0.5 \\
5 & 0.229 & 0.202 & 0.184 & 0.193 & 0.215 & 0.364 & 0.546 & 0.516 & 0.443 & 0.361 & 0.334 & 0.333 & 0.45 & 0.542 & 0.714 & 0.804 & 0.769 \\
6 & 0.189 & 0.189 & 0.177 & 0.208 & 0.266 & 0.358 & 0.443 & 0.374 & 0.366 & 0.323 & 0.342 & 0.34 & 0.434 & 0.5 & 0.626 & 0.68 & 0.661 \\
\multirow{2}{*}{ Biomass } & 0.165 & 0.152 & 0.148 & 0.169 & 0.202 & 0.295 & 0.384 & 0.357 & 0.308 & 0.259 & 0.255 & 0.254 & 0.336 & 0.404 & 0.528 & 0.58 & 0.539 \\
\hline
\end{tabular}


Long-term studies of cod diet and single and multispecies population model simulations indicate that cod predation is one of the most important factors impacting on the dynamics of the northern shrimp stock in the Barents Sea.

\section{Acknowledgement}

We thank very much Michaela Aschan of Institute Fiskeriforskning, Tromso, Norway, for kindly providing Norwegian survey data.

\section{References}

AJIAD, A. M., S. MEHL, K. KORSBREKKE, A. V. DOLGOV, V. A. KORZHEV, V. L. TRETYAK, and N. A. YARAGINA. 1992. Trophic relationships and feeding-dependent growth in the North-east Arctic cod. Interrelations between fish populations in the Barents Sea. Proc. of the fifth PINRO-IMR Symposium, Murmansk, 12-16 August 1991: 45-58.

ANON. MS 1999. Report of Arctic Fisheries Working Group. ICES C. M. Doc., No. ACFM:3: 276 p.

ASCHAN, M., B. BERENBOIM, and S. MUKHIN. MS 1995. Results of Norwegian and Russian investigations of shrimp (Pandalus borealis) in the Barents Sea and the Svalbard Area 1994. ICES C.M. Doc., No. K:11: $16 \mathrm{p}$.

BOGSTAD, B., and S. MEHL. 1992. The Northeast Arctic cod stock's consumption of various prey species in 19841989. Proc. of the fifth PINRO-IMR Symposium, Murmansk, 12-16 August 1991: 59-72.

BOGSTAD, B., G. LILLY, S. MEHL, O. K. PALSSON, and G. STEFÁNSSON. 1994. Cannibalism and year-class strength in Atlantic cod (Gadus morhua L.) in Arctoboreal ecosystems (Barents Sea, Iceland, and eastern
Newfoundland). ICES Mar. Sci. Symp., 198: 576-599. MEHL, S. 1986. Revised and modified programs for storing, analysis and presentation of taxonomic and quantitative stomach content data. Rapp. Havforskningsinstituttet, BN 8601, 62 p.

MEHL, S., and N. A. YARAGINA. 1992. Methods and results in the joint PINRO-IMR stomach sampling program. Interrelations between fish populations in the Barents Sea. Proceedings of the $5^{\text {th }}$ PINRO-IMR Symposium, Bergen, p. 5-16.

NILSSEN, E. M., T. PEDERSEN, C. C. E. HOPKINS, K. THY-HOLT, and J. G. POPE. 1994. Recruitment variability and growth of Northeast Arctic cod: influence of physical environment, demography, and predator-prey energetic. ICES Mar. Sci. Symp., 198: 449-470.

PONOMARENKO, I. YA., and N. A. YARAGINA. MS 1978. Year-to-year and seasonal fluctuations in the feeding of the Barents Sea cod on capelin in 19471976. ICES C.M. Doc., No. G:24: 19 p.

MS 1984. Seasonal, local and year-to-year variations in the feeding of Barents Sea cod on shrimp. ICES C.M. Doc., G:7: 20 p.

RASMUSSEN, B. 1953. On the geographical variations in growth and sexual development of the deep-sea prawn (Pandalus borealis). Fiskeridir.Skr., 10(3): 160 p.

STEFÁNSSON, G., U. SKULADOTTIR, and G. PETURSSON. MS 1994. The use of a stock production type model in evaluating the offshore Pandalus borealis stock of north Icelandic waters, including the predation of northern shrimp by cod. ICES C.M. Doc., K:25: 13 p.

TRETYAK, V. L., and V. A. KORZHEV. 1989. The effect of cannibalism on the strength of recruitment to commercial stock of Arcto-Norwegian cod. ICES Symp. on Multi-species Model, $20 \mathrm{p}$.

ZATSEPIN, V. I., and N. S. PETROVA. 1939. Feeding of commercial concentrations of cod in the southern Barents Sea (based on observations made in 19341938). Tr. PINRO, 5: 170 p. (in Russian). 